\title{
Characteristics of the systems of computer modelling and simulation of production processes
}

Marcin ROMANOWSKI, Krzysztof NADOLNY

DOI: 10.30464/jmee.2018.2.2.95

Cite this article as:

Romanowski M., Nadolny K. Characteristics of the systems of computer modelling and simulation of production processes. Journal of Mechanical and Energy Engineering, Vol. 2(42), No. 2, 2018, pp. 95-100.

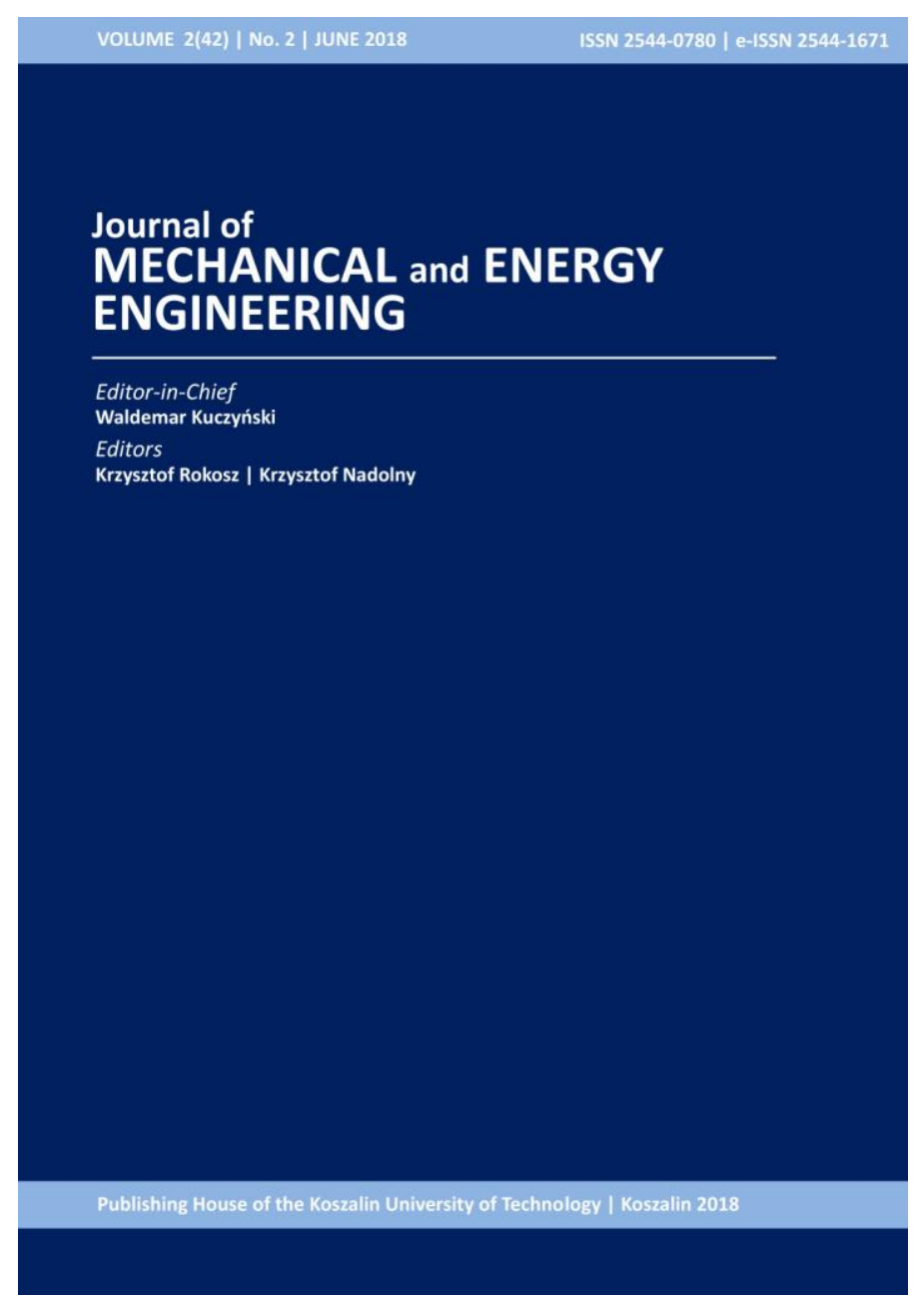

\section{Journal of Mechanical and Energy Engineering}

Website: jmee.tu.koszalin.pl

ISSN (Print): 2544-0780

ISSN (Online): 2544-1671

Volume: 2(42)

Number: 2

Year: 2018

Pages: $95-100$

Article Info:

Received 16 February 2018

Accepted 3 April 2018

\section{Open Access}

This article is distributed under the terms of the Creative Commons Attribution 4.0 (CC BY 4.0) International License (http://creativecommons.org/licenses/by/4.0/), which permits unrestricted use, distribution, and reproduction in any medium, provided you give appropriate credit to the original author(s) and the source, provide a link to the Creative Commons license, and indicate if changes were made. 


\title{
CHARACTERISTICS OF THE SYSTEMS OF COMPUTER MODELLING AND SIMULATION OF PRODUCTION PROCESSES
}

\author{
Marcin ROMANOWSKI ${ }^{1 *}$, Krzysztof NADOLNY ${ }^{2}$ \\ ${ }^{1 *}$ Faculty of Mechanical Engineering, Department of Production Engineering, Koszalin University \\ of Technology, Raclawicka 15-17, 75-620 Koszalin, Poland, e-mail: marcinro@wp.pl \\ ${ }^{2}$ Faculty of Mechanical Engineering, Department of Production Engineering, \\ Koszalin University of Technology, Poland
}

(Received 16 February 2018, Accepted 3 Aprl 2018)

\begin{abstract}
The article presents an analysis of the possibilities offered by the use of the modelling and simulation method in production management, by presenting its essence, types and examples of production process models. In addition, the article presents the characteristics of computer modelling and simulation systems which help to streamline production processes. The most commonly used programs such as AnyLogic, ShowFlow 2 and Rockwell Arena were described in detail. The concepts of modelling and simulation have been also clarified.
\end{abstract}

\section{INTRODUCTION}

The competition prevailing on the market forces producers to lower prices and at the same time to increase the quality of products. It is also necessary to shorten the production preparation time. All this forces companies to use computer technologies in this area.

Process planning is necessary to decide on the type of production. It indicates a detailed description of the operations needed to manufacture the products and its main goal is to achieve the highest possible production efficiency [7].

Automation is used in manufacturing operations and production processes. With the help of computers, designers can quickly implement and change production plans. By saving projects on computers, production process design time is reduced because there is no need to start from the beginning of each project, just edit the existing ones. Within the scope of the design of production system structures, there are usually large and varied collections of assortment items, described by the manufacturing technology in relation to workstations. These harvests should be analysed in the case of modernization of the structure of existing plants as well as when creating new plant structures. This is connected with making of the calculations, but they are extremely laborious. These activities concern in particular [7]:

- groups of assortment sets assigned to production units,

- dismantling of assortment of assortments assigned to production units - technological design of selected forms of organisation for a given production unit,

- workplace layout.

In these areas, it is necessary to use computer-aided support to improve calculations and achieve optimal solutions.

\section{DEFINITION OF MODELLING AND SIMULATION}

The model is a simplified object, its degree of similarity to the modelled object makes the study provide information that is relevant and useful for the purpose of the study. A simulation is an artificial reproduction of the properties of a given phenomenon or object that is difficult to observe, repeat or test. It consists in creating a simulation model of an object in the form of a mathematical and logical notation and depicting relationships describing the simulated object and its surroundings [9]. Figure 1 graphically illustrates modelling and simulation of production processes. 


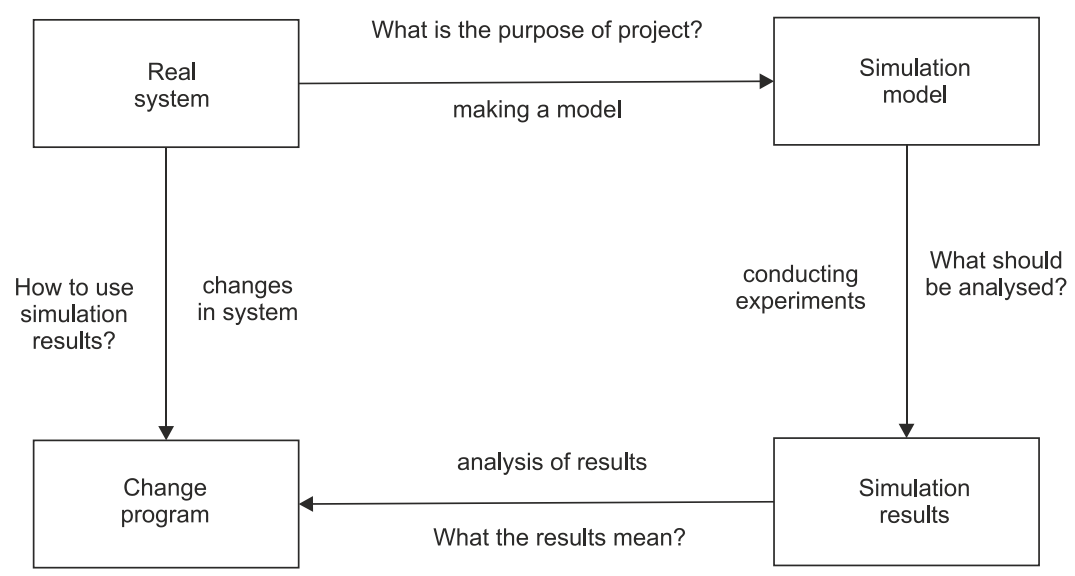

Fig. 1. Modelling and simulation of production systems [5]

Modelling of the production process, as well as its simulation, consists in creating a virtual model of the real production system, on which a number of experiments are carried out. As a result of this simulation, a number of reports are obtained by means of which subsequent activities are developed, e.g. the form of organisation of production sites or the type and number of means of transport are selected, as well as a programme of changes that can be made in an existing system in order to achieve the expected effect. The production system model tested may be modified and further simulated for different variants and parameters (new machines or new workstations) [1].

The following types of models are distinguished [6]:

- physical models - they show physical similarity between a real object and a model created within the scope of experience. They are characterized by the same physical and functional structure. An example of a physical model can be a scale model made of a trailer;

- mathematical models - they are presented in the form of an equation or a system of equations describing a given phenomenon, process or object. This type of model can be defined as a set of certain rules and dependencies, which can be used to predict the course of processes taking place in the examined object;

- Diagrammatic models - are used as twodimensional or three-dimensional drawing models drawn up on a specific scale, e. g. maps of material flow, value stream or plans for deployment of workstations. These models are a graphical presentation of real life layouts. Increasingly, drawing 3D models are being developed into physical models, e. g. by rapid prototyping.

Models can also be divided according to the way in which time is represented:

- statistical, the state of the system does not depend on time,
- dynamic, description of the variable model depends on time.

Due to the type of system to be modelled:

- discreet, unobtrusive state variables change discreetly,

- continuous, variable states change continuously over time.

Having regard to the way in which the variables are represented:

- stochastic, relations between objects are not clearly defined,

- deterministic, relations between objects are strictly defined.

In the case of simulation, three methods are distinguished:

- continuous simulation methods,

- discrete simulation methods,

- mixed simulation method (hybrid).

\section{INPUT DATA FOR MODELLING OF PRODUCTION PROCESSES}

To develop a production system model, it is necessary to collect information and input data with an appropriate level of quality, quantity and form. This is called the initial stage, which gives a certain view of the problem, including information on new methods that can be applied to solve it [1]. In addition, the input data allows the development of a process model with a sufficient detail according to the minimum number of objects required to achieve project objectives in the simplest way[8]. Basic information on the model of a manufacturing system in the engineering industry may include:

- information about the system facilities (type and number of machines, means of transport and their renovation plans, organization and distribution of production stands, number of employees),

- efficiency of the system (production plan for the analysed period, batch size, product range), 
- number and capacity of entry and exit and interoperational warehouses - bottlenecks,

- the technological process (so called technology marshrut) and the labour intensity of operations (time $T_{j}$ i $T_{p z}$ ),

- number and qualifications of employees (operators, setters, etc.),

- time of rebuilding the production to another type of product,

- the costs of materials, direct labour, direct labour, stationary labour, overheads, etc.,

- hypotheses for certain aspects of the problem, especially when there is a lack of specific data that will be verified experimentally,

- control system of the production system.

\section{PHASES OF MODEL CONSTRUCTION AND SIMULATION OF THE PRODUCTION PROCESS SYSTEM}

Building a simulation process model is a multistage task. On the basis of literature analysis, an algorithm has been developed for the construction, testing and experimental research of a simulation model of the production process (Fig. 2). This algorithm consists of several main phases: input data collection, pre-modelling, validation of results, primary modelling, and experiments and their final evaluation.

\section{TOOLS FOR COMPUTER MODELLING AND SIMULATION OF PRODUCTION SYSTEMS}

In recent years, there has been a significant development of methods and programs for computer simulation and methods and tools designed to process information on technological processes. The use of these tools in practice, the introduction of diagnostic processes becomes a necessity as well as an attribute of modernity. There are a number of programs that make it possible to trace back in a very short time the changes in the processes that may occur in the future [5].

A system is defined as a set of objects associated with specific interdependencies or interactions. Simulation modelling is one of the most important techniques supporting the design of robotic flexible production systems as well as production management.

Until recently, computer simulation was the domain of large companies, which could afford to buy both computer hardware and expensive software. The turbulent development of information technology has made it more accessible. Modelling and simulation software has also developed significantly. Simulation packages have become more comprehensive and universal.

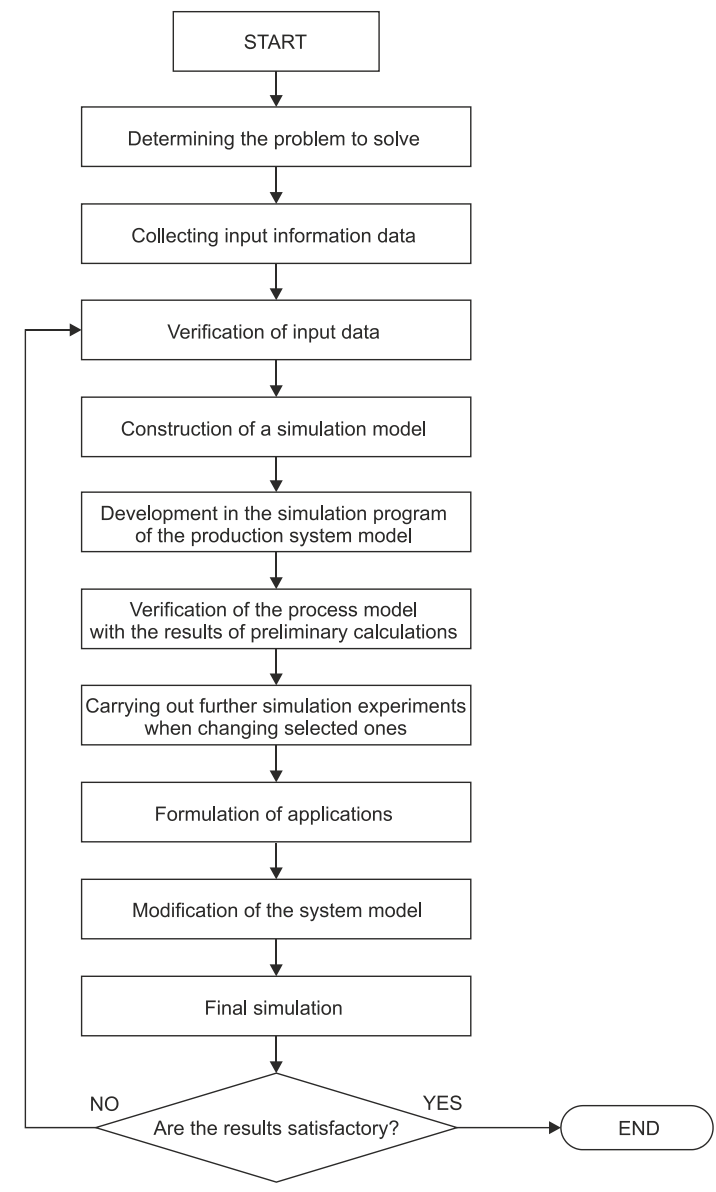

Fig. 2. The small claims algorithm of the main steps of developing a simulation model of production process $[1,3,9]$

Various simulation programs are now available on the market, ranging from the simplest mathematical models based on mathematical models to the most complex ones, with a stochastic device enabling e.g. adjustment of input data to the correct distribution, simulation of robot or machine tool failures with its own extensive libraries, animation creation environment, 3D graphics, rich tools for presentation of output data from simulation.

The main advantages of visual-interactive simulation include [9]:

- better understanding of the model,

- easier verification and validation of the model,

- possibility of interactive experimentation,

- improved presentation and interpretation of results,

- improved communication with the model,

- adaptation to potential use in problem-solving groups.

The required features of modern simulation programs are:

- generating random numbers from a homo-geneous probability distribution, 
- generating random values from a specified probability distribution,

- progressive simulation time,

- determination of subsequent results and current control of the simulation code,

- possibility of adding and deleting records,

- data collection and analysis,

- reporting of results,

- detection of environmental errors.

Generally speaking, simulation and modelling software can be divided into three main groups: general purpose software language spreadsheets and specialised software.

From the design point of view, simulation systems such as Rockwell Arena, AnyLogic, ShowFlow 2 or Microsoft Visio are the most useful in logistics.

Rockwell Arena - was presented in 2000 by Rockwell Automation. It consists of a special group of tools that allow you to evaluate the alternatives of the best approaches to optimization and process efficiency. The program impresses with its simplicity of operation. The user creates certain models for experimentation, determines and selects the modules (graphic icons) that play the role of individual processes. The program then determines the performance of a system consisting of indicators such as cost, resource availability, capacity, cycle time and the use of machines and individual workstations. Arena is an application that works in a Microsoft Windows environment and all the commands, commands and rules characteristic for this environment also apply here. It gives the user the possibility to use ready functional modules, from which the main simulation model is created. These modules are shown in Figure 3 , and each module has its own design for faster simulation. A great advantage of Arena is the ability to import objects created in another program designed for modelling different types of processes [13].

AnyLogic was created between 1998 and 2000 by the Distributed Computer Network (DCN). The aim of the group was to create modern simulation software. The project focused on the application of simulation methods, performance analysis, stochastic system behavior, optimization and visualization of various processes. This tool was called AnyLogic because it was able to use all three known modelling methods: system dynamics, discrete event simulation and agentbased modelling [10].

AnyLogic is more complex than the Rockwell Arena. Library tools and facilities allow fast modelling of various fields such as manufacturing and logistics, business processes and human resources. AnyLogic software allows to build hybrid simulation models, both in the form of graphs and animations. Such a graphical presentation of the phenomenon supports educational processes, and also facilitates the understanding of relationships appearing in the analysed system. The main application of this software is to model supply chains and simulate logistics processes. This includes managing the flow of goods and information in a planned network of suppliers, carriers, shippers and other logistics operators. A screenshot from AnyLogic is shown in Figure 4.

It is a software that has a very clear and easy-touse interface, which puts it at the forefront of the most popular production process simulation programs [11].

ShowFlow 2 - used to create simulation, modelling and analysis of processes during production, transport and logistics. It deals with the optimization of production processes, among others: organization, scheduling, production cycle efficiency and presentation of raw material flows in a given time[14]. An example of a simulation model in ShowFlow is shown in Figure 5.

Microsoft Visio - a program for creating diagrams necessary to visualize production processes. It is defined as universal software for creating various types of diagrams and diagrams compliant with BPMN (Business Process Modelling Notation) standards. It has many templates for schema creation.

There are many different types of diagrams, such as example [16]:

- IDEFO diagrams - describe processes as a transition between individual activities, in such a way that each activity changes the input parameters into output and control parameters. It consists of a diagram of the context, a subordinate diagram and a tree with knots,

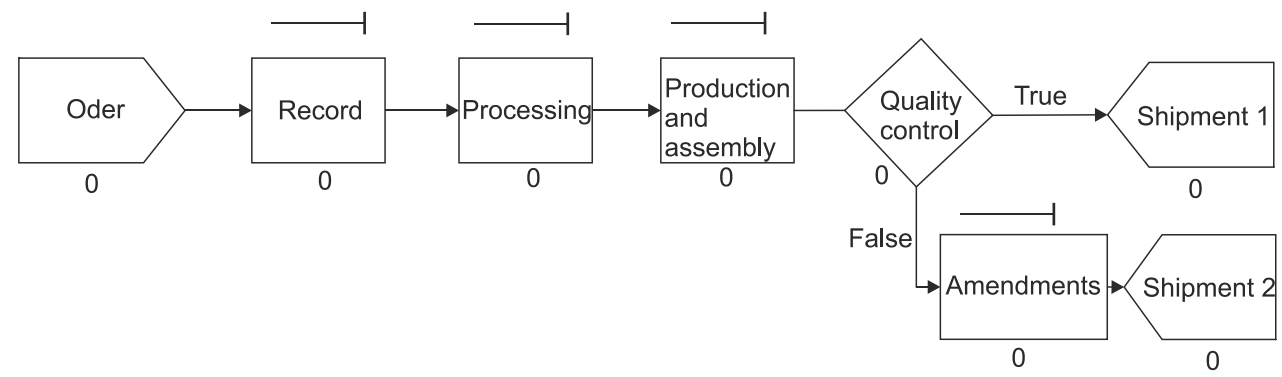

Fig. 3. modules of the Rockwell Arena software [6] 


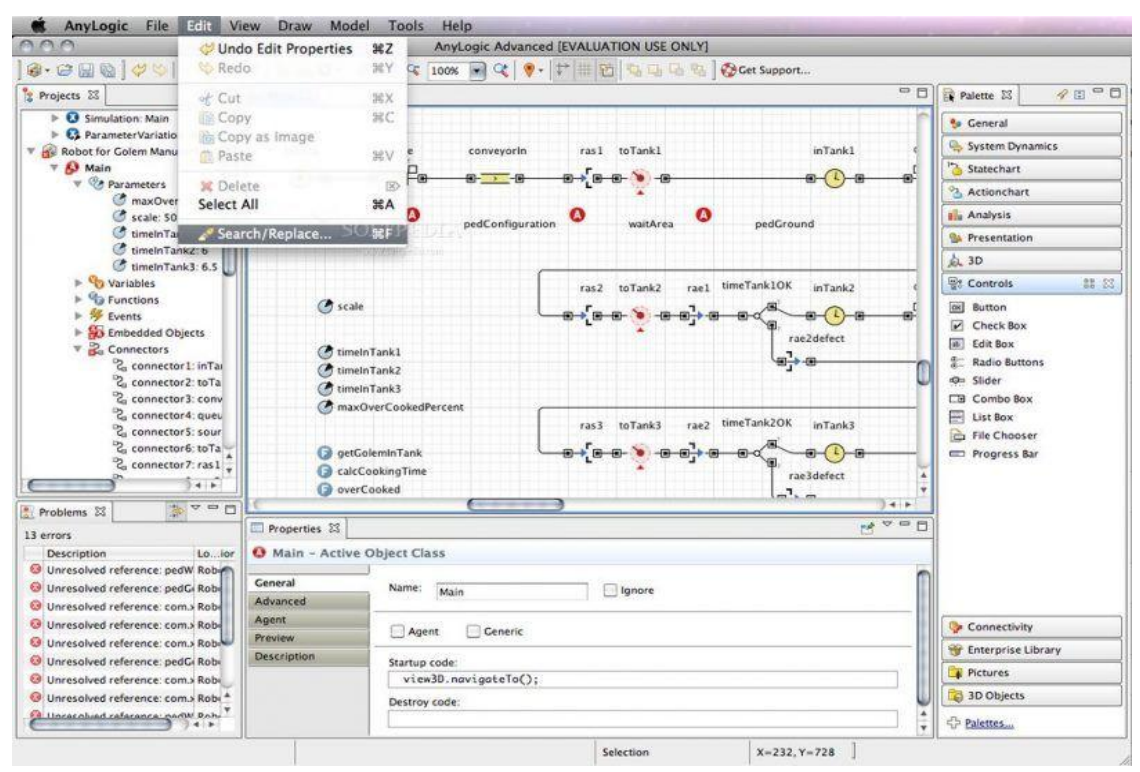

Fig. 4. Screenshot from AnyLogic - simulation of filling tanks [15]

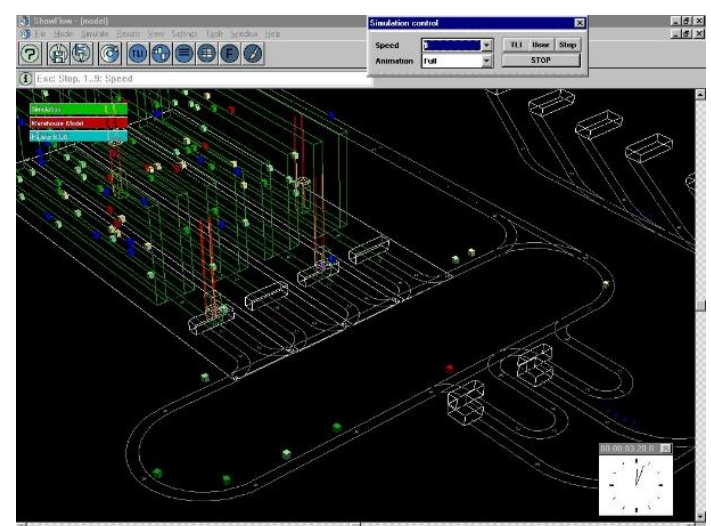

Fig. 5. Automated Storage and Retrieval System, model in Show Flow 2 [14]

There are many different types of diagrams, such as example [16]:

- IDEFO diagrams - they describe processes as a transition between individual activities, in such a way that each activity changes the input parameters into output and control parameters. It consists of a diagram of the context, a subordinate diagram and a tree with knots,

- cross-functional schemes - they allow for a convenient description of processes passing between departments in the organisation. In this description, one may include both the steps, steps and steps in which the processes are located. This is one of the most difficult diagrams to perform, and Microsoft Visio makes it easier to do so,

- flow diagrams - creation of such a diagram consists in moving relevant objects onto the screen and connecting them together.

Figure 6 shows an example of a Microsoft Visio enterprise operating equipment.

\section{CONCLUSIONS}

The article presents systems for computer modelling and simulation allowing one to improve production processes. Modelling and simulation are characterized as concepts. The most frequently used programs such as AnyLogic, ShowFlow 2 or Rockwell Arena were discussed. The stages of model construction and simulation of the production system were also described. The main conclusions drawn from this information are as follows:

1. Modelling and simulation systems allow to analyze many variants of created designs of production process operation and to select one that is most apt before implementing improvements.

2. Modelling of production systems facilitates decision making or determines features and parameters of systems that are unknown.

3. With the help of the computer simulation reports, one may develop a strategy of action, create a concept and arrive at the desired conclusions.

4. Modelling and production process simulation techniques enable rapid analysis of the process together with its various variants on a computerised system model.

5. The most commonly used manufacturing process modelling and simulation programs include: Rockwell Arena, AnyLogic, and Microsoft Visio.

\section{References}

1. Ciszak O. (2007). Modelling and Simulation of the final assembly using the Flexsim software, in: 3th International Conference Virtual Design and Automation - VIDA, "Innovation in Product and Process Development", 28-29.06.2007, Poznan, Poland, Conference materials: summary pp. 25 , full paper on CD. 


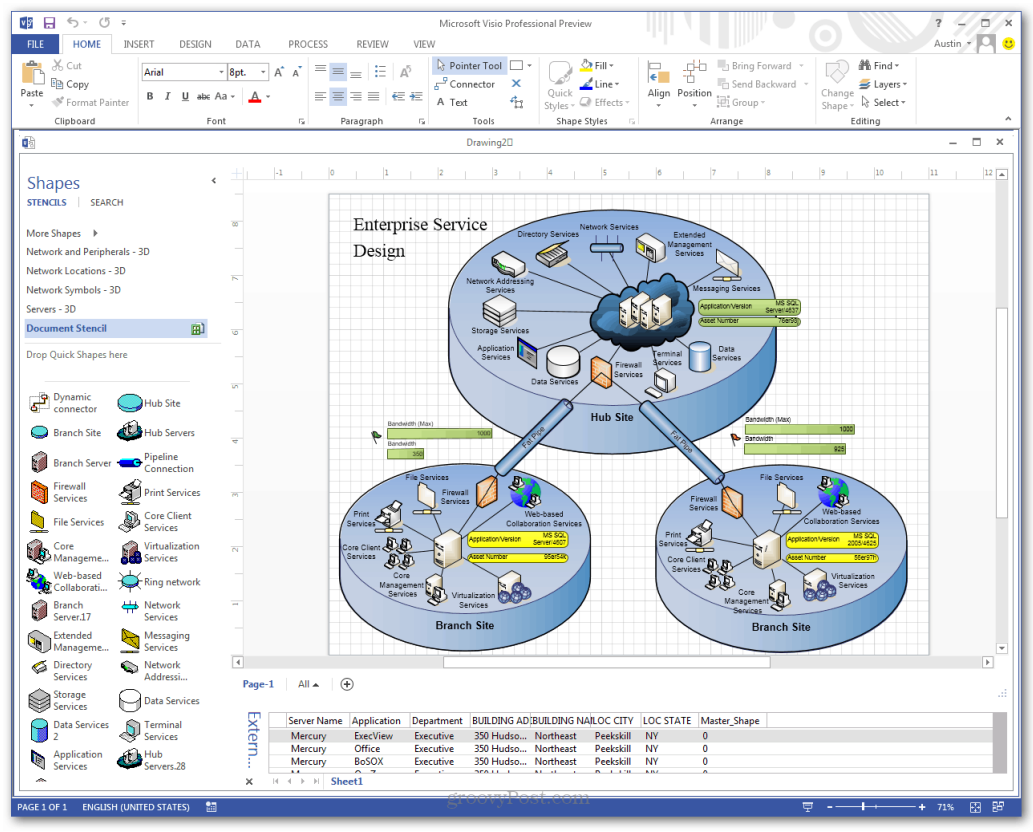

Fig. 6. The enterprise operating equipment drawn in Microsoft Visio [12]

2. Ciszak O. (2007) Computer-assisted modelling and simulation of production processes, Scientific booklets of Poznan Polytechnic. (in Polish)

3. Ciszak O., Żurek J. (2006). Balancing of vertical milling centre final assembly line, ATMiA, 2006, Vol. 26, No. 2, pp. 239-245.

4. Gregor M., Haluškova M., Hromada J., Košturiak J., Matuszek J. (1998). Simulation of Manufacturing System, Publishing house of the Technical University Lodz - Branch in Bielsko-Biala.

5. Kluska-Nawarecka S., Wojcik T. (1993). Application of the computer to predict the failures and casting defects. Plant Group Training on Design and Manufacture of Cast Spare Parts. Ed. Foundry Research Institute, Krakow.

6. Maciąg A., Pietron R., Kukla S. (2013), Forecasting and simulation in the enterprise, Economic Publishing House. (in Polish)

7. Mazurczak J. (2004). Designing production system structures, Poznan University of Technology Publishing House. (in Polish)

8. Zdanowicz R. (2002) Modelling and simulation of manufacturing processes, Gliwice, Publishing House of the Silesian University of Technology, Gliwice. (in Polish)

9. Zdanowicz R., Świder J. (2005). Modelling and Simulation of Production Systems in the Enterprise DYNAMICS Program, Publishing House of the Silesian University of Technology, Gliwice. (in Polish)

10. http://www.anylogic.com, (Access: September 2017)

11. http://www.czasopismologistyka.pl, (Access: December 2017)

12. https://www.groovypost.com/reviews/microsoft-visioexplained/, (Access: January 2018)

13. http://www.mechanik.media.pl, (Access: September 2017)

14. http://www.showflow.com, (Access: November 2017)

15. https://www.topbestalternatives.com/anylogic/, (Access: September 2017)

16. http://www.procesowcy.pl, (Access: September 2015)

\section{Biographical notes}

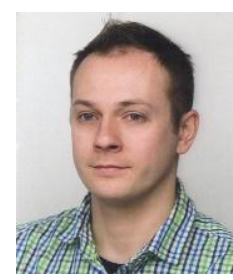

Marcin Romanowski received his M.Sc. degree in Exploitation Port and Fleet (specialisation: transport) from Maritime Academy in Gdynia. He works as a Logistics and Procurement Manager in PRO-WAM Company in Koszalin and simultaneously studies at second year of Ph.D studies at the Faculty of Mechanical Engineering of Koszalin University of Technology. He is interested in the cutting and milling technology as well as production cost minimalization and technological foresight.

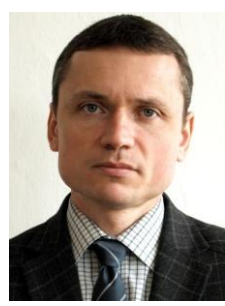

Krzysztof Nadolny received his M.Sc. degree in Mechanics and Machine Design and next Ph.D (with honors) as well as the D.Sc. degree in Machinery Construction and Operation from Koszalin University of Technology, in 2001, 2006 and 2013, respectively. Since 2006 , he has been a researcher in the Department of Production Engineering at the Koszalin University of Technology, where currently he works as an associated professor and head of research-didactic team for production planning and control. His scientific interests focus on problems concerning machining processes and tools, efficiency, monitoring and diagnostics of machining processes as well as tribology. He has participated in 2 international and 3 national research projects, presenting results of his work at 10 international and 21 national conferences, published more than 200 scientific papers in international and national journals, book chapters, as well as conference proceedings. $\mathrm{He}$ is also the author of 4 monographs and 9 national patents. 